\title{
A Modified Bursting Energy Index for Evaluating Coal Burst Proneness and Its Application in Ordos Coalfield, China
}

\author{
Xuewei Liu ${ }^{1,2, * \mathbb{D}}$, Quansheng Liu ${ }^{3}$, Bin Liu $^{1}$ and Yongshui Kang ${ }^{1}$ \\ 1 State Key Laboratory of Geomechanics and Geotechnical Engineering, Institute of Rock and Soil Mechanics, \\ Chinese Academy of Sciences, Wuhan 430071, China \\ 2 Department of Civil Engineering, Monash University, Clayton, VIC 3168, Australia \\ 3 The Key Laboratory of Safety for Geotechnical and Structural Engineering of Hubei Province, \\ School of Civil Engineering, Wuhan University, Wuhan 430072, China \\ * Correspondence: liuxw@whrsm.ac.cn; Tel.: +86-27-87199185
}

Received: 6 January 2020; Accepted: 31 March 2020; Published: 5 April 2020

\begin{abstract}
Coal burst is a type of dynamic geological hazard in coal mine. In this study, a modified bursting energy index, which is defined as the ratio of elastic strain energy at the peak strength to the released strain energy density at the post-peak stage, was proposed to evaluate the coal burst proneness. The calculation method for this index was also introduced. Two coal mines (PJ and $\mathrm{TJH}$ coal mines) located in Ordos coalfield were used to verify the validity of the proposed method. The tests results indicate that modified bursting energy index increases linearly with increasing uniaxial compressive strength. The parameter $\mathrm{A}$, which is used to fit relation between total input and elastic strain energy density, has a significant effect on the modified bursting energy index. A large value of parameter A means more elastic strain energy before the peak strength while a small value indicates most of input energy was dissipated. Finally, the coal burst proneness of these two coal mines was evaluated with the modified index. The results of modified index are consistent with that of laboratory tests, and more reasonable than that from original bursting energy index because it removed the dissipated strain energy from the total input strain energy density.
\end{abstract}

Keywords: coal mine; rock mechanics; coal burst proneness; bursting energy index; elastic strain energy density

\section{Introduction}

Coal burst, which involves the sudden and violent ejection of coal into roadways, is one of the most serious disaster encountered in coal mines. Since 1738, the first coal burst was issued in Britain; this type of geological disaster was reported in most of countries, including Canada, South Africa, USA, India, France, and so on. For example, in the United States, two coal bursts occurred at Crandall Canyon Mine in Utah in 2007 and resulted in the death of nine workers, which is one of the most severe coal burst accidents [1]. In Australia, more than 900 fatal incidents occurred in coal mines from 1957 and 2008 [2]. Especially, in China, it is one of most serious disaster in deep mining [3]. For instance, a burst disaster was reported in Longjiabao coal mine with 9 fatalities and 12 severely injured on June 6th, 2019. Several months ago, on October 20th, 2018, a coal burst occurred in Yuncheng coal mine and resulted in 21 fatalities. Therefore, the coal burst severely threatens personnel safety and may delay the project schedule in coal mine. Therefore, studies on the occurrence, predication, and control of coal burst events have great scientific and engineering significance $[4,5]$.

A large number of researches have been conducted on the coal burst, which general can be classified into following two types: One is monitoring methods and the other is control techniques. For the 
first one, the methods, such as drilling bits method, micro-seismic monitoring (including multi-index monitoring technique [6], multiplet approach method [7], frequency spectrum analysis method [8], micro-seismic activity, energy characteristics, signal characteristics, spatiotemporal distribution law, and micro-seismic precursory characteristics of rock burst hazard [9-13]), electromagnetic emissions (including electromagnetic emission graded warning model [14] and non-contact mine pressure comprehensive evaluation method [15-17]), and the integrated micro-seismic and electromagnetic radiation method [18] have been widely used. On the other hand, many control techniques, including preventative controls and mitigating controls, have been proposed for controlling coal burst during mining [19]. The preventative controls are a technique by optimizing the mine design to avoid burst event, such as pillar design (including yield-stable-yield pillar [20], yield-stable pillar [21], critical pillar [22], and abutment pillars [23]), protective coal seam [24], and the shape and direction of roadways [25]. The mitigating controls are measures to further decrease the impact of coal burst. For example, directional hydraulic fracturing [26], the constant-resistance and large-deformation bolt [27], and de-stress drilling [28].

There are two different perspectives or scales to discuss the coal burst. One is coal sample physical mechanical properties. The coal burst proneness indexes, which can be obtained by the laboratory tests conducted on coal samples, is used to judge coal burst proneness with corresponding standards. The other perspective is mining. Except the physical properties of coal sample, the coal burst is also determined by mining methods (different unloading rate, pillar design, and mining speed), geological features (such as geo-stress, joints), and even roadway direction. In this paper, the work is focused on the first perspective.

Coal burst proneness is an inherent characteristic of coal, which can be aroused by the sudden release of elastic energy under unloading conditions. Therefore, the evaluation of coal burst proneness of coal samples is the first step and essential for the predication and controlling of coal burst. At present, many discriminant indexes and criteria, based on energy, strength, or failure duration, have been proposed [6]. For instance, Dai et al. [29] studied the feasibility of evaluating the coal burst proneness by modulus index, which is defined as the ratio of softening modulus at the post-peak to the elastic modulus before the peak strength. $\mathrm{Xu}$ et al. [30] proposed a new energy release rate index, which was successfully verified by predicting the position of rock burst in a coal mine. Gong et al. [31] developed a peak-strength strain energy storage index and a new criterion for rock burst proneness, which was validated by estimating the rock burst proneness of nine rock materials. Besides, the elastic strain potential energy index, the decrease modulus index, and brittleness index were also proposed in the literature [32].

Among these indexes, four coal burst proneness indexes, namely uniaxial compressive strength $\left(R_{c}\right)$, failure duration time $(D T)$, elastic strain energy index $\left(W_{e t}\right)$, and bursting energy index $\left(K_{e}\right)$, were widely used and recommended by Chinese standard (GB/T 25217.2-2010). Then, Yang et al. [33] extended these indexes into Australia coal mines. Su et al. [34] discussed the relationship between these indexes and indicated that the bursting energy index may overestimate the coal burst proneness. Generally, the design of support in burst-prone areas are totally different from that without bursting proneness. For the coal mine without bursting proneness, the control method can be confirmed by surrounding rock grade, including normal bolt, cable, shouting concrete, and steel arch. However, in burst-prone areas, the control techniques are more complex. Some pretreatment measures are de-stress drilling and directional hydraulic fracturing. Besides, the pillar design, coal seam, and bolt pattern should satisfy dynamic deformation. Therefore, overestimation of the coal burst proneness may cause the original safe coal mine to be wrongly classified as probable bursting, which will lead to designing change. Otherwise, the underestimation of coal burst proneness will threaten the productivity severely. However, the original bursting energy index $\left(K_{e}\right)$ is defined as the ratio of total input energy density before the peak strength to the released strain energy density after peak strength. The total input energy density at the peak point includes elastic and dissipated strain energy density. The elastic strain energy keeps accumulating during loading process while dissipated strain energy is 
dissipated during the loading stage. Therefore, the original bursting energy index may overestimate the coal burst proneness.

In order to solve this problem, a modified bursting energy index, defined as the ratio of elastic strain energy at the peak strength and the released strain energy density after peak strength, was proposed to evaluate the coal burst proneness. The calculation method for this index was also introduced. The reliability of the present index is verified through tests on two typical coal mines in Ordos coalfield, China.

\section{Brief Descriptions of Coal Burst Proneness Indexes}

According to Chinese standard (GB/T 25217.2-2010) [35], the coal burst proneness can be classified into three different grades: none, low, and high. The specific index values for each grade are listed in Table 1.

Table 1. Coal burst proneness classification. (Chinese standard, GB/T 25217.2-2010).

\begin{tabular}{|c|c|c|c|c|}
\hline \multicolumn{2}{|c|}{ Burst Proneness } & \multirow{2}{*}{$\begin{array}{c}\text { None } \\
D T>500\end{array}$} & \multirow{2}{*}{$\begin{array}{c}\text { Low } \\
50<D T \leq 500\end{array}$} & \multirow{2}{*}{$\begin{array}{c}\text { High } \\
D T \leq 50\end{array}$} \\
\hline \multirow{4}{*}{ Index } & DT (ms) & & & \\
\hline & $W_{\text {et }}$ & $W_{\mathrm{et}}<2$ & $2 \leq W_{\mathrm{et}}<5$ & $W_{\text {et }} \geq 5$ \\
\hline & $K_{\mathrm{e}}$ & $K_{\mathrm{e}}<1.5$ & $1.5 \leq K_{\mathrm{e}}<5$ & $K_{\mathrm{e}} \geq 5$ \\
\hline & $R_{\mathrm{c}}(\mathrm{MPa})$ & $R_{\mathrm{C}}<7$ & $7 \leq R_{\mathrm{C}}<14$ & $R_{\mathrm{C}} \geq 14$ \\
\hline
\end{tabular}

Through the uniaxial compression tests on the standard coal samples, uniaxial compressive strength (UCS) and dynamic failure duration time, which is defined as the time span from the peak stress to complete failure of coal specimen, can be easily obtained. Figure 1 shows the calculation method and definition of the index $W_{e t}$. As shown in Figure $1, W_{e t}$ is the ratio of elastic strain energy density to the dissipated strain energy density when the axial loading $\sigma_{k}$ is equal to $75 \sim 85 \%$ of the peak strength of coal specimen. The index $W_{e t}$ can be calculated by a single cyclic loading-unloading uniaxial compression test. The formula for index $W_{e t}$ is listed as follows.

$$
W_{e t}=\frac{u_{a e}^{k}}{u_{a d}^{k}}
$$

where $u_{a e}^{k}, u_{a d}^{k}$ are the elastic strain energy density and the dissipated strain energy density when the axial loading $\sigma_{k}$, respectively. The definition of these two parameters can be expressed as the following equation:

$$
\begin{gathered}
u_{a}^{k}=\int_{0}^{\varepsilon_{k}} \sigma_{l}(\varepsilon) d \varepsilon \\
u_{a e}^{k}=\int_{\varepsilon_{k 0}}^{\varepsilon_{k}} \sigma_{u}(\varepsilon) d \varepsilon \\
u_{a d}^{k}=u_{a}^{k}-u_{a e}^{k}
\end{gathered}
$$

where $u_{a}^{k}$ is the total input energy density during loading process. Parameters $\varepsilon_{k}$ and $\varepsilon_{k 0}$ are strain at the unloading point and the permanent strain after unloading. $\sigma_{l}(\varepsilon)$ and $\sigma_{u}(\varepsilon)$ are functions for curves of loading and unloading. 


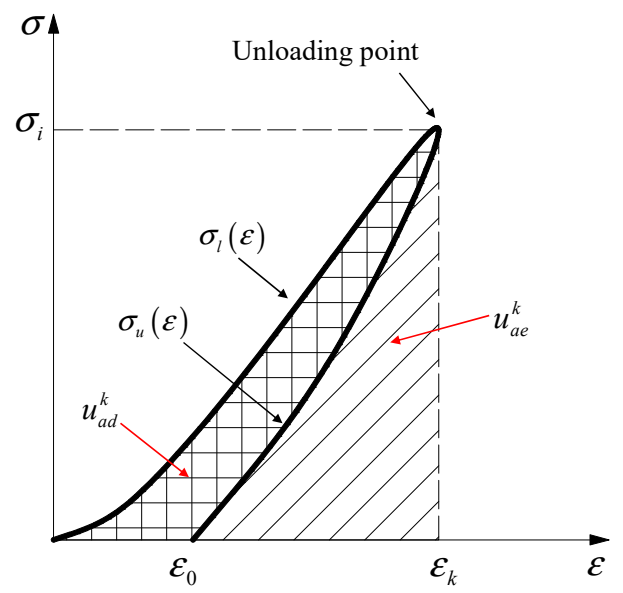

Figure 1. Calculation of elastic strain energy index.

For the index $K_{e}$, which is defined as the ratio of accumulated strain energy density before the peak strength $u_{a}$ to the released strain energy density after peak strength $u_{r}$, can be calculated with uniaxial compression test. As shown in Figure 2, the formula for index $K_{e}$ is listed as follows:

$$
K_{e}=\frac{u_{a}}{u_{r}}
$$

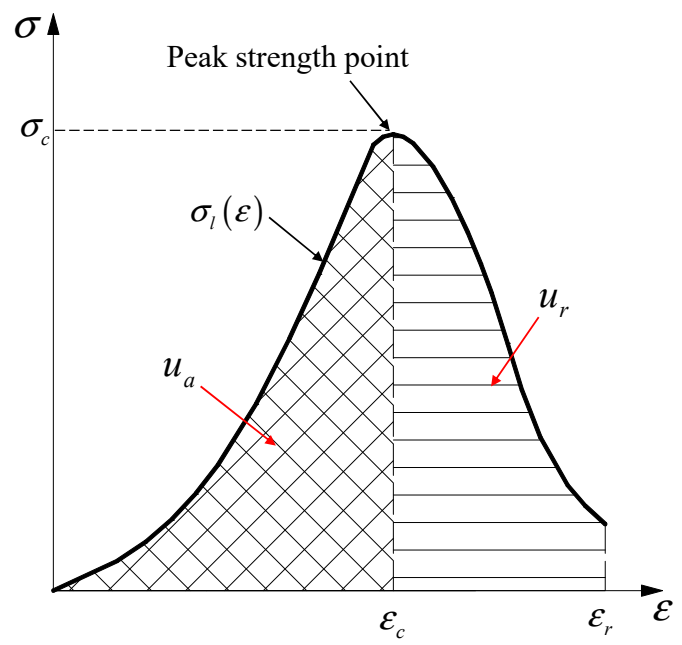

Figure 2. Calculation of bursting energy index.

Similarly, the parameters $u_{a}$ and $u_{r}$ can be expressed by following equations:

$$
\begin{gathered}
u=\int_{0}^{\varepsilon_{r}} \sigma_{l}(\varepsilon) d \varepsilon \\
u_{a}=\int_{0}^{\varepsilon_{c}} \sigma_{l}(\varepsilon) d \varepsilon \\
u_{r}=u-u_{a}
\end{gathered}
$$

where $u$ is the total energy density during entire loading process. Parameters $\varepsilon_{\mathcal{c}}$ and $\varepsilon_{r}$ are the strain at the peak point and ultimate failure point. From Equations (1) and (5), it can be found that both of the indexes $W_{e t}$ and $K_{e}$ can determine energy accumulating and releasing ability of coal.

As shown in Figure 3, it is known that the total input energy density at the peak point includes two parts: elastic strain energy density $u_{a e}$ and dissipated strain energy density $u_{a d}$. The elastic 
strain energy keeps accumulating during loading process. For the dissipated strain energy, it will be dissipated during the loading stage because of the closure of micro-cracks, material damage, and plastic deformation. As a result, dissipated strain energy has little effect on the energy released at the post-peak stage.

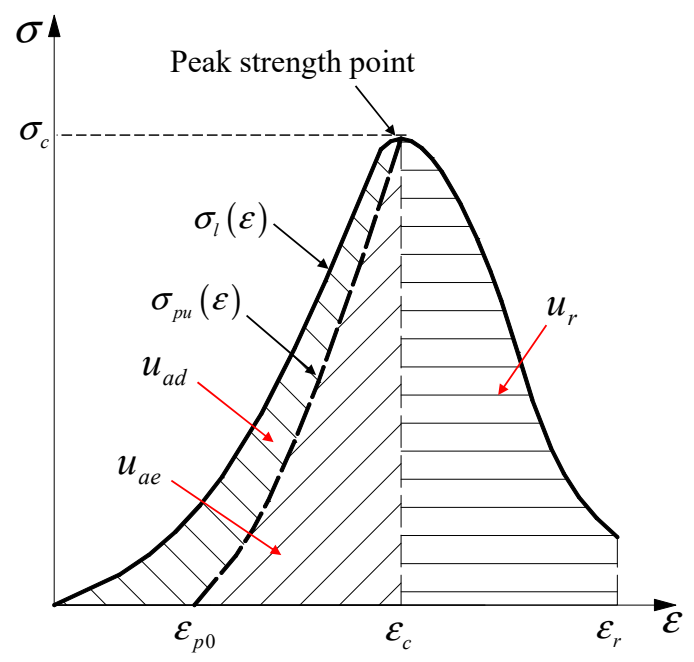

Figure 3. Calculation of modified bursting energy index.

However, from Figure 2 and Equation (5), it indicates that both elastic and dissipated strain energy are used to calculate the bursting energy index, which may overestimate the coal burst proneness, especially for that of strong plastic coal.

\section{Modified Bursting Energy Index}

\subsection{Definition of the Modified Index}

In this section, a modified bursting energy index $K_{e}^{p}$, which is defined as the ratio of elastic strain energy at the peak strength to the released strain energy density after peak strength and can be expressed by the following equation:

$$
K_{e}^{p}=\frac{u_{a e}}{u_{r}}
$$

where the parameters $u_{a e}$ and $u_{a d}$ can be expressed as follows:

$$
\begin{gathered}
u_{a e}=\int_{\varepsilon_{p 0}}^{\varepsilon_{c}} \sigma_{p u}(\varepsilon) d \varepsilon \\
u_{a d}=u_{a}-u_{a e}
\end{gathered}
$$

where parameter $\varepsilon_{p 0}$ is permanent strain after unloading from the peak point.

Obviously, the key to calculate the index $K_{e}^{p}$ is obtaining the elastic strain density at the peak strength point $u_{a e}$ accurately. Because of the dispersion and heterogeneity of the coal specimen strength [36], it is impossible to conduct the unloading test on coal specimens at the peak strength point. Gong et al. [37] proposed a new method to calculate the peak elastic strain energy storage index for different rock specimens, such as sandstone, granite, and marble. In this study, this method was introduced and validated to obtain elastic strain density at the peak point for coal specimens.

\subsection{Calculation Method for Index $K_{e}^{p}$}

According to the results of Gong et al. [31], a series of single cyclic loading-unloading uniaxial compression under different stress level $\mathrm{k}$ (the ratio of unloading point stress and uniaxial compressive 
strength) first are carried out. For each cyclic loading-unloading test, the total input and elastic strain energy density can be calculated and the results indicated that the $u_{a e}^{k}$ (elastic strain energy density when unloading at stress level $\mathrm{k}$ ) increases lineally as the $u_{a}^{k}$ (total input strain energy density when unloading at stress level $\mathrm{k}$ ) increases, which can be expressed as follows:

$$
u_{a e}^{k}=A u_{a}^{k}+B
$$

where the parameters A and B are fitting coefficients and they are constant for the same rock specimens. Further, the elastic strain energy $u_{a e}$ can be calculated by the following equation:

$$
u_{a e}=A u_{a}+B
$$

Therefore, the modified bursting energy index can be calculated combining the Equations (9) and (13). Based on the previous analysis, the following method is recommended to obtain the index $K_{e}^{p}$ :

(a) Conduct a group of uniaxial compression tests on coal specimens to obtain their average UCS;

(b) Conduct a series of single cyclic loading-unloading uniaxial compression tests under different stress level $k$, and the parameters $u_{a e}^{k}$ and $u_{a}^{k}$ are calculated by integration;

(c) According to the different $u_{a e}^{k}$ and $u_{a}^{k}$ at stress level $k$, the parameters $\mathrm{A}$ and $\mathrm{B}$ can be fitted by Equation (13);

(d) According to the results of uniaxial compression tests in step a), calculate the strain energy density before the peak strength $u_{a}$ by Equation (7);

(e) Calculate the elastic strain energy $u_{a e}$ using Equation (13);

(f) Finally, obtain the modified bursting energy index $K_{e}^{p}$ by combining Equations. (9), (13), and (8)

\section{Coal Burst Proneness Evaluation in Coal Mines}

In this section, two typical coal mines, namely Pojianghaizi (PJ) and Tangjiahui (TJH), were used to discuss the validity of the proposed method by comparing coal burst proneness with the Chinese standard (GB/T 25217.2-2010) [35] and test results.

As shown in Figure 4, PJ coal mine is located in northwest Ordos city with a distance about $40 \mathrm{~km}$ and $\mathrm{TJH}$ coal mine located in northeast Ordos city with a distance about $130 \mathrm{~km}$. The PJ coal mine has a width of $4.6 \mathrm{~km}$, length of $13.2 \mathrm{~km}$, and 668 million ton of coal resources. The mainly mineable coal seams are coal \#3, coal \#4, and coal \#5 with mining depths in the range of 506-640 m under the ground, approximately. The TJH coal mine has a width of $5.1 \mathrm{~km}$, length of $8.5 \mathrm{~km}$, and 310 million ton of coal resources, and contains three mainly mineable coal seams namely coal \#4, coal \#5, and coal \#6 with different depths varying from $357 \mathrm{~m}$ to $576 \mathrm{~m}$ under the ground surface.

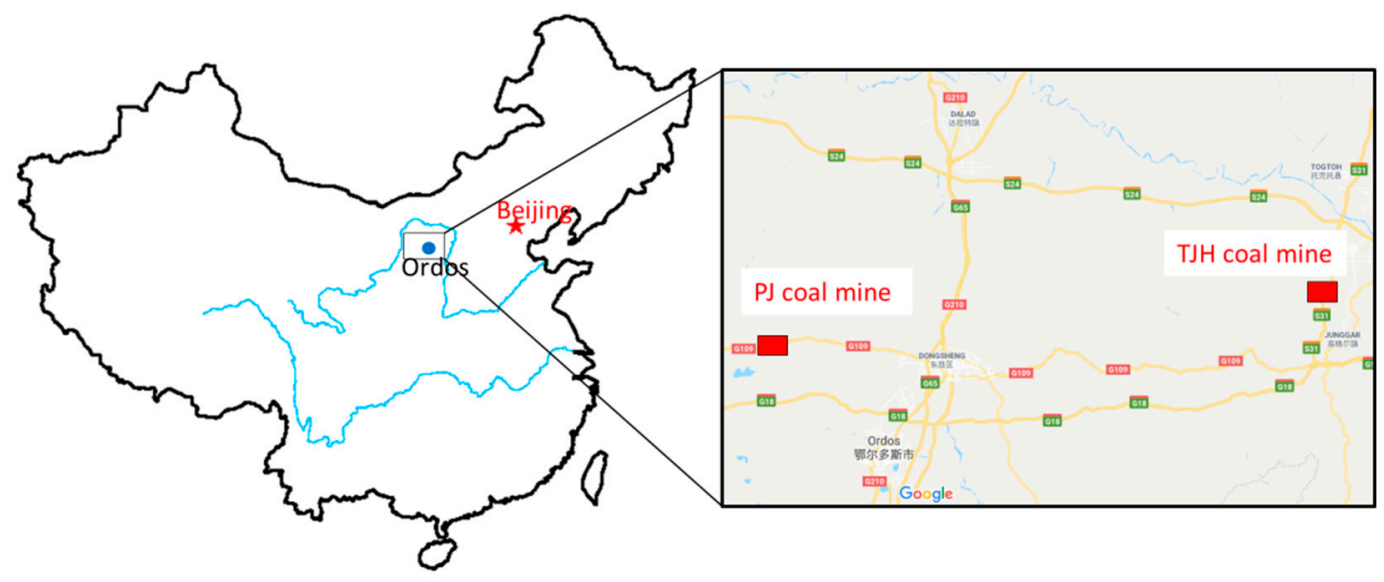

Figure 4. Locations of $\mathrm{PJ}$ and $\mathrm{TJH}$ coal mines. 
To obtain the standard coal specimens, some coal blocks (Figure 5a) were collected from PJ and TJH coal mines first, and then, the collected coal blocks were cut into standard specimens of length $50 \mathrm{~mm}$, width $50 \mathrm{~mm}$, and height $100 \mathrm{~mm}$ (Figure 5b). The loading surfaces of all specimens were then polished in accordance with the standards of the International Society for Rock Mechanics [38].

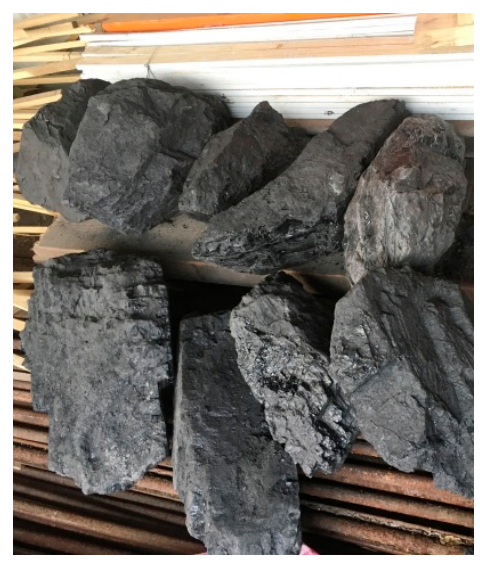

(a)

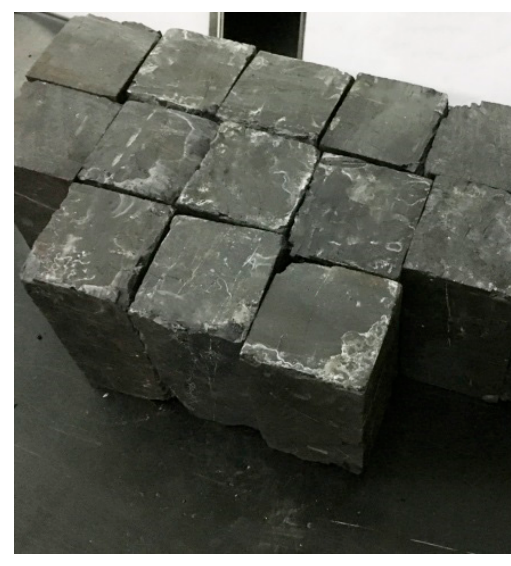

(b)

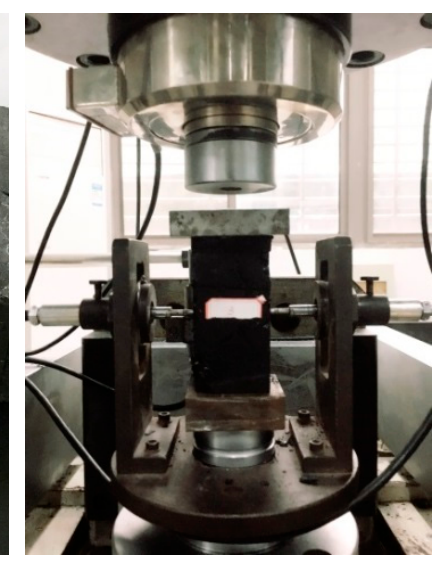

(c)

Figure 5. Coal specimens laboratory test procedures: (a) Coal blocks; (b) standard coal specimens; (c) Loading tests on RMT-150C.

The tests were conducted by the RMT-150C servo-controlling testing machine, as shown in Figure $5 c$, and the maximum vertical loading capacity and confining pressure of RMT-150C are $1000 \mathrm{kN}$ and $50 \mathrm{MPa}$, respectively. This system has two controlling modes during test and can record data simultaneously. According to Liang et al. [39], the uniaxial compressive strength increases as loading rate increases and the recommended loading strain rate is from $10^{-5}$ to $10^{-3} \mathrm{~s}^{-1}$. Therefore, in this study, displacement control mode with a constant speed of $0.002 \mathrm{~mm} / \mathrm{s}$ was selected.

\subsection{PJ Coal Mine}

The specimens were collected from 113101 work face with depth of about $522 \mathrm{~m}$. As listed in Table 2, three groups of single cyclic loading-unloading uniaxial compression tests were carried out on coal specimens. For each group, there are four specimens with different unloading stress level k. The calculated $u_{a}^{k}, u_{a e}^{k}$, and $u_{a \mathrm{~d}}^{k}$ are listed in Table 2 and the representative loading-unloading stress-strain curves for each group are shown in Figure 6.

Table 2. Strain energy density of coal specimens in PJ coal mine.

\begin{tabular}{|c|c|c|c|c|c|c|}
\hline Group No. & Specimen No. & $\begin{array}{c}\text { Stress Level } \\
k\end{array}$ & $\begin{array}{c}u_{a}^{k} \\
\left(\mathrm{~mJ} / \mathrm{mm}^{3}\right)\end{array}$ & $\begin{array}{c}u_{a e}^{k} \\
\left(\mathrm{~mJ} / \mathrm{mm}^{3}\right)\end{array}$ & $\begin{array}{c}u_{a \mathrm{~d}}^{k} \\
\left(\mathrm{~mJ} / \mathrm{mm}^{3}\right)\end{array}$ & $W_{e t}$ \\
\hline \multirow{4}{*}{ Group 1} & A-1 & $52 \%$ & 0.0130 & 0.0098 & 0.0032 & 3.02 \\
\hline & A-2 & $63 \%$ & 0.0165 & 0.0124 & 0.0041 & 3.06 \\
\hline & A-3 & $79 \%$ & 0.0241 & 0.0199 & 0.0042 & 4.76 \\
\hline & A-4 & $86 \%$ & 0.0307 & 0.0233 & 0.0074 & 3.14 \\
\hline \multirow{4}{*}{ Group 2} & B-1 & $62 \%$ & 0.0199 & 0.0156 & 0.0043 & 3.60 \\
\hline & B-2 & $73 \%$ & 0.0244 & 0.0192 & 0.0052 & 3.72 \\
\hline & B-3 & $84 \%$ & 0.0294 & 0.0225 & 0.0069 & 3.27 \\
\hline & B-4 & $93 \%$ & 0.0342 & 0.0272 & 0.0070 & 3.87 \\
\hline \multirow{4}{*}{ Group 3} & C-1 & $51 \%$ & 0.0168 & 0.0128 & 0.0040 & 3.21 \\
\hline & $C-2$ & $67 \%$ & 0.0239 & 0.0186 & 0.0053 & 3.51 \\
\hline & $C-3$ & $78 \%$ & 0.0308 & 0.0249 & 0.0059 & 4.23 \\
\hline & $C-4$ & $86 \%$ & 0.0384 & 0.0298 & 0.0086 & 3.44 \\
\hline
\end{tabular}




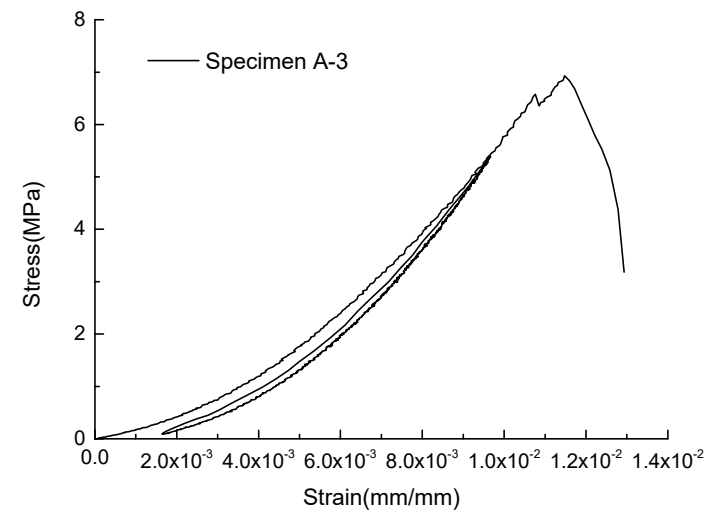

(a)

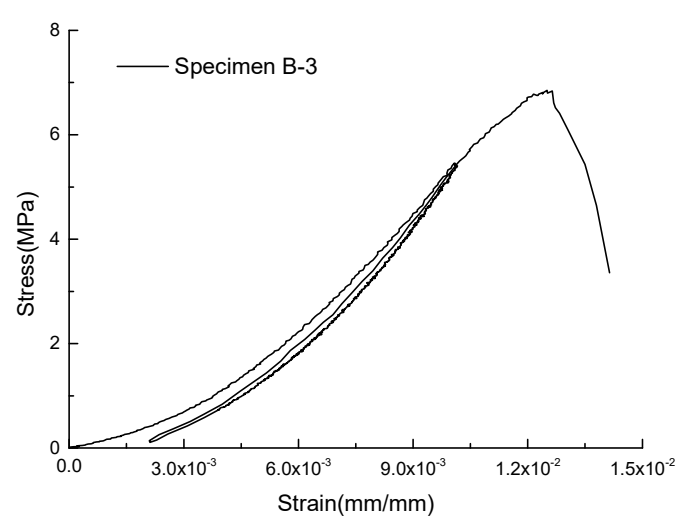

(b)

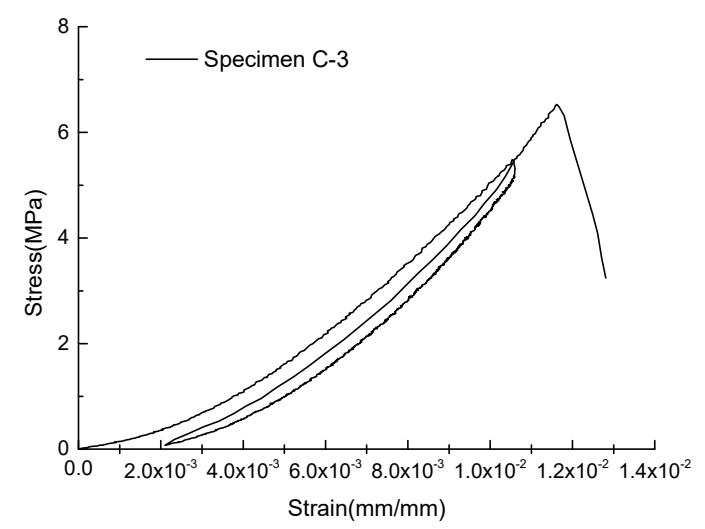

(c)

Figure 6. Representative loading-unloading stress-strain curves for each group: (a) Specimen A-3; (b) Specimen B-3; (c) Specimen C-3.

Based on Equation (12), the date listed in Table 2 were used to study the relationship between elastic strain energy density and total input strain energy density. The linear fitting equations for each group of specimens are listed as follows:

$$
\begin{cases}u_{a e}^{k}=0.7912 u_{a}^{k}-3.24 \times 10^{-4} & \left(R^{2}=0.9753\right) \cdots \text { Group } 1 \\ u_{a e}^{k}=0.7952 u_{a}^{k}-3.27 \times 10^{-4} & \left(R^{2}=0.9914\right) \cdots \text { Group } 2 \\ u_{a e}^{k}=0.7960 u_{a}^{k}-3.52 \times 10^{-4} & \left(R^{2}=0.9925\right) \cdots \text { Group 3 }\end{cases}
$$

where the parameter $R^{2}$ is correlation coefficient.

The fitting curves are shown in Figure 7 and data are listed in Table 3. From Equation (14) and Figure 7, it can be found that the parameters A for the three groups are 0.7912, 0.7952, and 0.7960 respectively. The average value of parameter $\mathrm{A}$ is 0.7419 and the percentage errors listed in Table 3 showed that all the groups are lower than $0.5 \%$, indicating that parameter A for the same coal type is nearly constant. On the other hand, for the parameter B, the average value is $-3.43 \times 10^{-4}$ and percentage errors for the three groups are $5.539 \%, 4.665 \%$, and $2.624 \%$ respectively, which is quite acceptable. Therefore, it can be concluded that the parameters A and B for a specific coal type can be considered as constant and the average values can be used for calculation in Equation (13). 


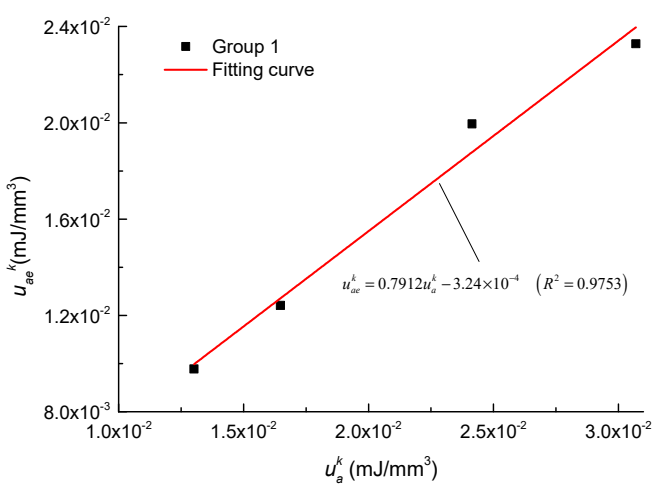

(a)

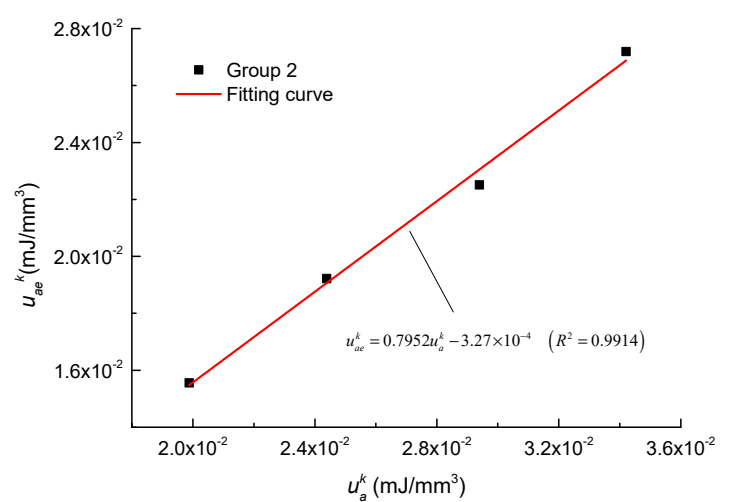

(b)

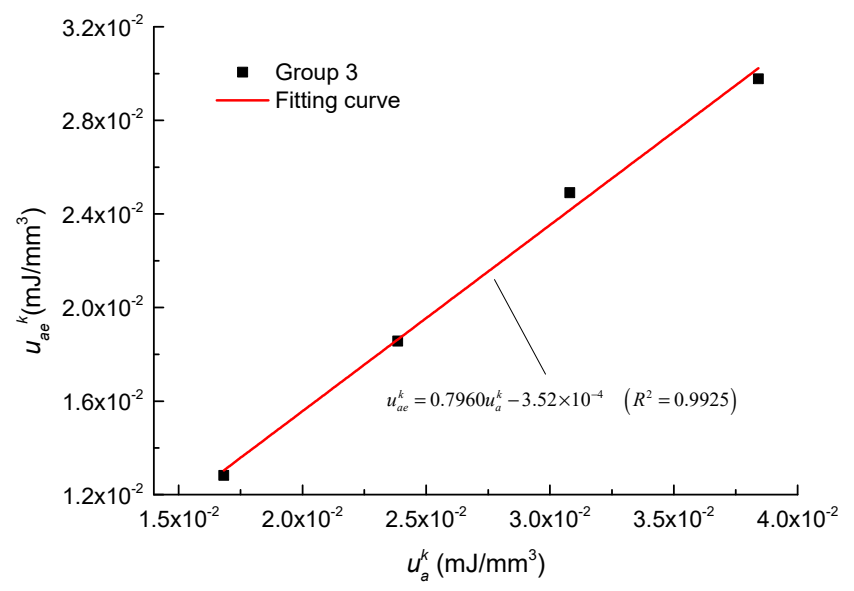

(c)

Figure 7. Relationship between elastic strain energy density and total input strain energy density for PJ coal mine: (a) Group 1; (b) Group 2; (c) Group 3.

Table 3. Fitting parameters of A and B for three groups of tests.

\begin{tabular}{ccccccc}
\hline Group No. & A & $\begin{array}{c}\text { Average Value } \\
\text { of A }\end{array}$ & $\begin{array}{c}\text { Percentage } \\
\text { Error (\%) }\end{array}$ & $\begin{array}{c}\text { B } \\
\left(\times \mathbf{1 0}^{-4}\right)\end{array}$ & $\begin{array}{c}\text { Average Value } \\
\text { of B }\end{array}$ & $\begin{array}{c}\text { Percentage } \\
\text { Error (\%) }\end{array}$ \\
\hline Group 1 & 0.7912 & & 0.365 & -3.24 & & 5.539 \\
Group 2 & 0.7952 & 0.7491 & 0.139 & -3.27 & $-3.43 \times 10^{-4}$ & 4.665 \\
Group 3 & 0.7960 & & 0.239 & -3.52 & & 2.624 \\
\hline
\end{tabular}

In addition, it should be noted that the correlation coefficients $\left(\mathrm{R}^{2}\right)$ are $0.9753,0.9914$, and 0.9925 for Group 1, Group 2, and Group 3 respectively, indicating that there is a strong linear relationship between parameters $u_{a e}^{k}$ and $u_{a}^{k}$. The results in here are consistent with that obtained by Gong et al. [31].

Figure 8 shows the stress-strain curves of four typical coal specimens under uniaxial compression condition. It can be found that the stress-strain behavior of all the coal specimens contains three different stages, i.e., fissure closure, elastic deformation, and post-peak. At the fissure closure stage, the curves show a downward concave shape because the closure of pre-existing micro fissures and pores in coal. With the increasing of axial loading, stress-strain behavior turns into elastic deformation and post-peak stages gradually. An obvious stress drop (from point B to C in Figure 8. For example, for specimen $\mathrm{K}-4$, the stress decreases from 6.95 MPa to 2.31 MPa while strain increases from 0.0095 to 0.0114.) can be observed in the post-peak stage, meaning that the coal specimens have the characteristics of the brittle failure. 


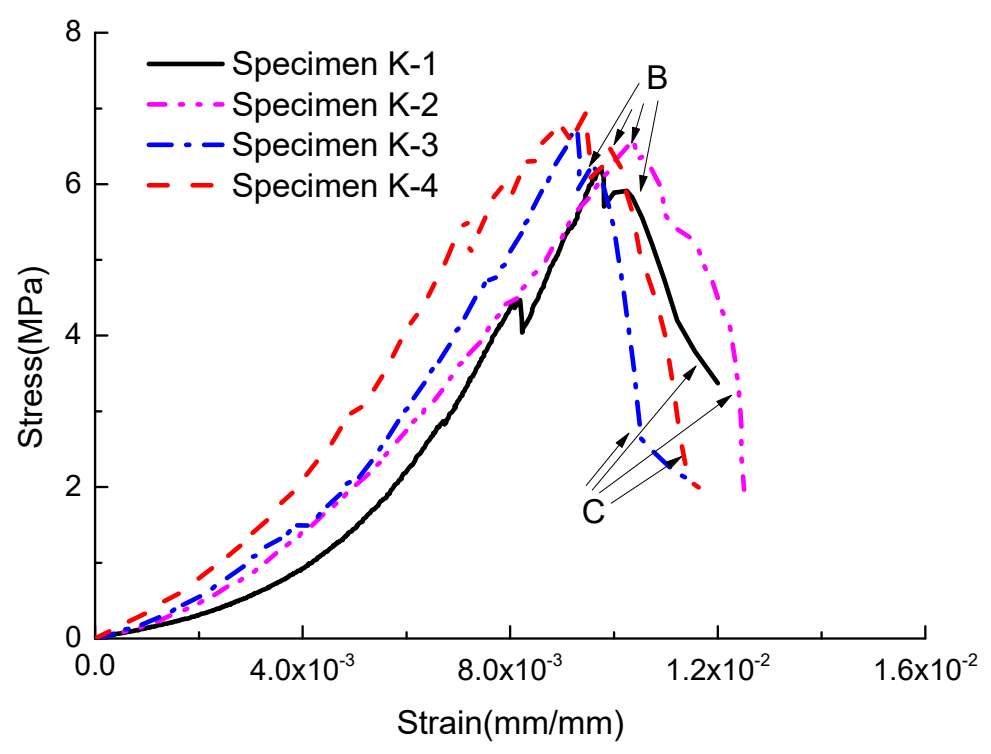

Figure 8. Stress-strain curves of coal specimens under uniaxial compression condition.

According to the average values of A and B listed in Table 2 and integration method, $u_{a}$ and $u_{r}$ can be calculated by Equations (6)-(8) and $K_{e}^{p}$ can be calculated by Equations (9)-(11). The data is listed in Table 4. In addition, the peak-strength strain energy storage index $W_{e t}^{p}$, which was proposed by Gong et al. [37], has also been calculated by the following equation:

$$
W_{e t}^{p}=\frac{u_{a e}}{u_{a d}}
$$

Table 4. Calculated energy parameters for the typical test results.

\begin{tabular}{|c|c|c|c|c|c|c|c|c|c|}
\hline $\begin{array}{c}\text { Specimen } \\
\text { No. }\end{array}$ & $\begin{array}{c}R_{c} \\
(\mathrm{MPa})\end{array}$ & $\begin{array}{c}u \\
\left(\mathrm{~mJ} / \mathrm{mm}^{3}\right)\end{array}$ & $\begin{array}{c}u_{a} \\
\left(\mathrm{~mJ} / \mathrm{mm}^{3}\right)\end{array}$ & $\begin{array}{c}u_{a e} \\
\left(\mathrm{~mJ} / \mathrm{mm}^{3}\right)\end{array}$ & $\begin{array}{c}u_{a d} \\
\left(\mathrm{~mJ} / \mathrm{mm}^{3}\right)\end{array}$ & $\begin{array}{c}u_{r} \\
\left(\mathrm{~mJ} / \mathrm{mm}^{3}\right)\end{array}$ & $K_{e}$ & $W_{e t}^{p}$ & $K_{e}^{p}$ \\
\hline K-1 & 6.21 & 0.0336 & 0.0216 & 0.0168 & 0.0048 & 0.0120 & 1.7962 & 3.509 & 1.3978 \\
\hline $\mathrm{K}-2$ & 6.65 & 0.0374 & 0.0253 & 0.0198 & 0.0056 & 0.0121 & 2.0978 & 3.557 & 1.6374 \\
\hline $\mathrm{K}-3$ & 6.74 & 0.0343 & 0.0230 & 0.0179 & 0.0051 & 0.0113 & 2.0336 & 3.528 & 1.5846 \\
\hline $\mathrm{K}-4$ & 6.97 & 0.0375 & 0.0273 & 0.0214 & 0.0060 & 0.0102 & 2.6732 & 3.578 & 2.0892 \\
\hline
\end{tabular}

From Table 4, it can be found that the index $W_{e t}^{p}$ for the four specimens are 3.509, 3.557, 3.528, and 3.578, respectively with an average value of 3.543. Besides, the percentage errors of these four specimens for index $W_{e t}^{p}$ are all lower than $1.0 \%$ and in the range of $0.38 \%-0.98 \%$, which means that the fluctuation of index $W_{e t}^{p}$ is very small for a same type of coal specimen.

In addition, index $K_{e}^{p}$ for the four specimens are 1.3978, 1.6374, 1.5846, and 2.0892, respectively with an average value of 1.6772. The percentage errors of these four specimens for index $K_{e}^{p}$ are all larger than $2 \%$ and the maximum percentage error is $24.57 \%$ for specimen $\mathrm{K}-4$. The results indicate that the index $K_{e}^{p}$ are varying with different specimens. Besides, for the index $K_{e}$, the average value is 2.1502 , which is larger than that of index $K_{e}^{p}$ because the dissipated strain energy density has not been considered in index $K_{e}^{p}$.

According to Table 1 and tests results, the four indexes recommended by Chinese standard (GB/T 25217.2-2010) [35] are obtained and the coal burst proneness grade for each index are judged respectively, as shown in Table 5. 
Table 5. Test result and coal burst proneness of PJ coal mine.

\begin{tabular}{ccccc}
\hline Index & $\boldsymbol{D} \boldsymbol{T}(\mathbf{m s})$ & $\boldsymbol{W}_{\text {et }}$ & $\boldsymbol{K}_{\mathbf{e}}$ & $\boldsymbol{R}_{\mathbf{c}}(\mathbf{M P a})$ \\
\hline & 1850 & 4.76 & 1.80 & 6.21 \\
Test results & 752 & 3.27 & 2.10 & 6.65 \\
& 2002 & 4.32 & 2.03 & 6.74 \\
Average & 503 & 4.59 & 2.67 & 6.97 \\
Burst proneness & 1276.8 & 4.24 & 2.15 & 6.64 \\
\hline
\end{tabular}

From Table 5, it is easily found that the values of elastic strain energy index $W_{e t}$ and bursting energy index $K_{e}$ are 4.24 and 2.15, which indicates a low coal burst proneness. Further, as seen in Table 4 , the average value of parameter $W_{e t}^{p}$ is 3.53. According to the research result of Gong et al. [31], when index $W_{e t}^{p}$ is in the range of $2 \sim 5$, the rock burst proneness grade is low. Therefore, the coal burst proneness results from peak-strength strain energy storage index $W_{e t}^{p}$ is consistent with that from Chinese standard (GB/T 25217.2-2010) [35].

According to the above laboratory tests results [31,40], one can conclude that no injected coal fragments with almost intact sample indicates no burst proneness, a minor ejected fragment with slight ejection sound and some macroscopic cracks means low burst proneness, and a large amount of ejected fragments with loud sound and severely broken sample indicates high proneness.

Figure 9 shows the ultimate failure mode of coal specimens under uniaxial compression test. From Figure 9, it is evident that the coal spalling and split cracks can be observed on the specimen surface. Further, these spalled coal fragments fell off from the specimens with slight sound and formed some voids on the surfaces, which demonstrates that the coal burst proneness is low. Therefore, the test results validated that the index $K_{e}^{p}$ with a value of 1.6772 indicating a low coal burst proneness.
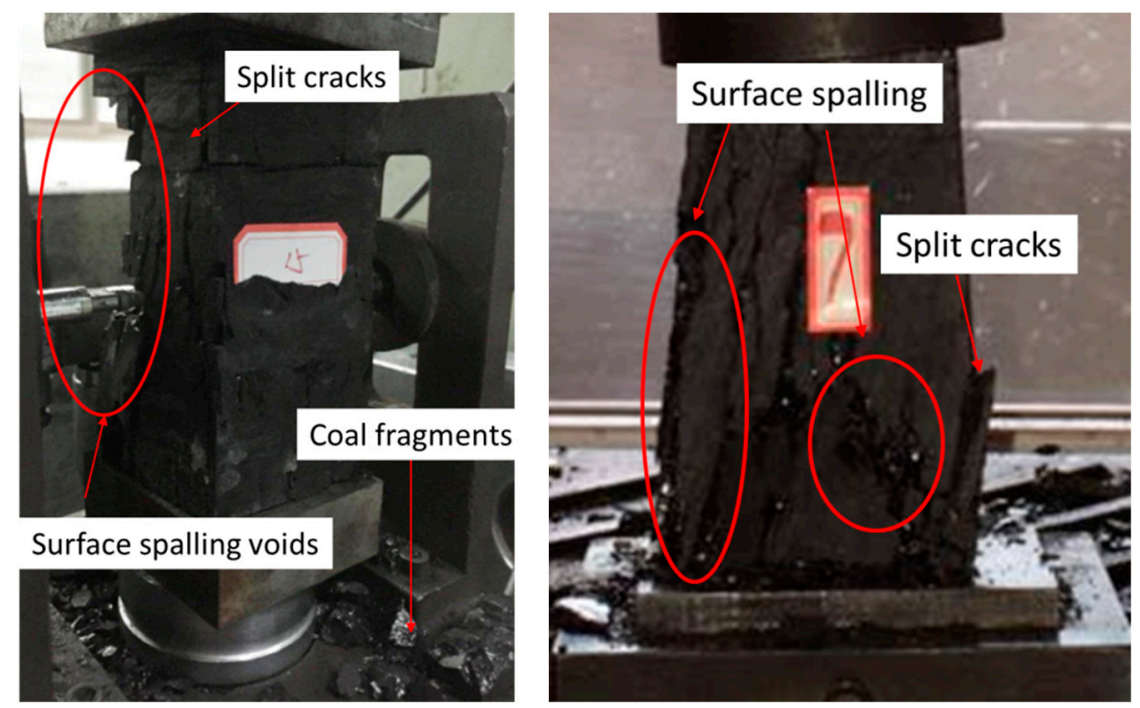

Figure 9. Ultimate failure mode of coal specimens in PJ coal mine.

\subsection{TJH Coal Mine}

The specimens of TJH coal mine were collected from 63,103 work face with depth of about $464 \mathrm{~m}$. According to the results of PJ coal mine, the parameters A and B for a specific coal type can be considered as constant, therefore, only one group of single cyclic loading-unloading uniaxial compression tests were carried out on TJH coal specimens. Calculated data of $u_{a}^{k}, u_{a e}^{k}$, and $u_{a \mathrm{~d}}^{k}$ for four specimens with different unloading rates is listed in Table 6. When unloading rate $\mathrm{k}$ increases from $51 \%$ to $89 \%$, the index $W_{\text {et }}$ varying from 1.44 to 1.48 with the percentage error in the range of $1.41 \%-10.12 \%$. 
The results indicate that elastic strain energy index $W_{\text {et }}$ is not a constant but has a large fluctuation even for a same type of specimen.

Table 6. Strain energy density of coal specimens in TJH coal mine.

\begin{tabular}{ccccccc}
\hline Group No. & $\begin{array}{c}\text { Specimen } \\
\text { No. }\end{array}$ & $\begin{array}{c}\text { Stress Level } \\
\boldsymbol{k}\end{array}$ & $\begin{array}{c}\boldsymbol{u}_{\boldsymbol{a}}^{k} \\
\left(\mathbf{m J} / \mathbf{m m}^{3}\right)\end{array}$ & $\begin{array}{c}\boldsymbol{u}_{a e}^{k} \\
\left(\mathbf{m J} / \mathbf{m m}^{3}\right)\end{array}$ & $\begin{array}{c}\boldsymbol{u}_{a \mathrm{~d}}^{k} \\
\left(\mathbf{m J} / \mathbf{m m}^{3}\right)\end{array}$ & $W_{\text {et }}$ \\
\hline \multirow{4}{*}{ Group 1 } & D-1 & $51 \%$ & 0.0149 & 0.0088 & 0.0061 & 1.44 \\
& D-2 & $66 \%$ & 0.0195 & 0.0109 & 0.0085 & 1.28 \\
& D-3 & $81 \%$ & 0.0200 & 0.0119 & 0.0081 & 1.47 \\
& D-4 & $89 \%$ & 0.0216 & 0.0129 & 0.0087 & 1.48 \\
\hline
\end{tabular}

Furthermore, relationship between elastic strain energy density and total input strain energy density under different unloading rates were investigated and the linear fitting equation can be expressed as follows:

$$
u_{a e}^{k}=0.5979 u_{a}^{k}-2.54 \times 10^{-4}\left(R^{2}=0.9452\right)
$$

The fitting curve for this group of coal specimens is shown in Figure 10. From Equation (16) and Figure 10, it can be found that the parameters A and B for TJH coal mine specimens are 0.5979 and $-2.54 \times 10^{-4}$, respectively.

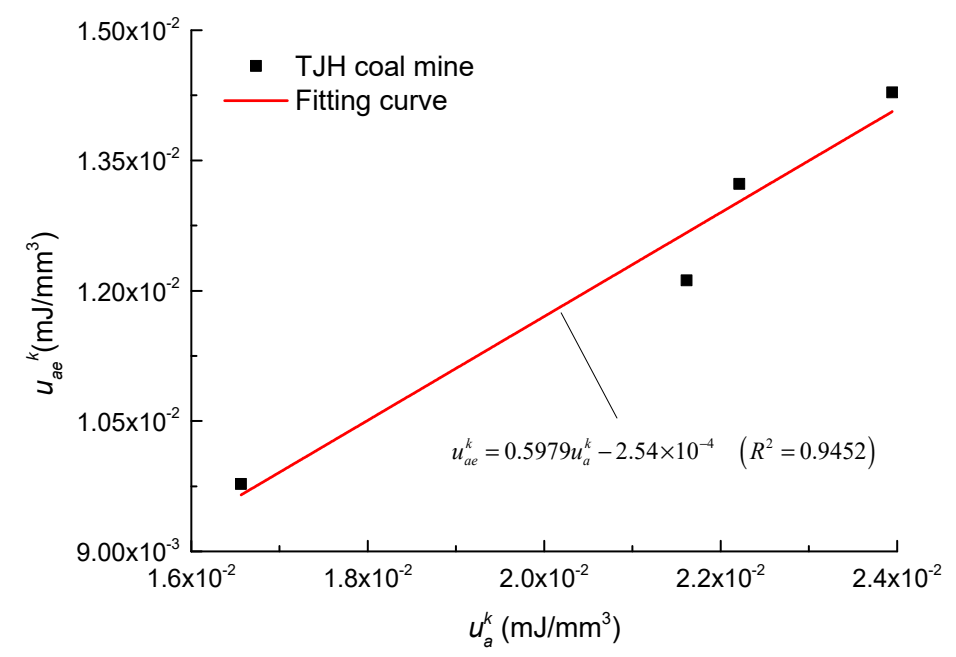

Figure 10. Relationship between elastic strain energy density and total input strain energy density for TJH coal mine.

Figure 11 shows stress-strain curves of four typical specimens in TJH coal mine. Like PJ coal mine, the stress-strain behavior also contains fissure closure, elastic deformation, and post-peak stages. The difference is that the fissure closure stage maintains turns into elastic deformation stage until strains approximately are $0.33 \%, 0.42 \%, 0.40 \%$, and $0.48 \%$ for specimen $\mathrm{T}-1, \mathrm{~T}-2, \mathrm{~T}-3$, and $\mathrm{T}-4$ respectively, indicating that a large number of micro fissures and pore exist in the coal.

According to the uniaxial compression stress-strain curves and values of parameters A and B listed in Equation (16), the energy density parameters $u, u_{a}, u_{r}$, and indexes $K_{e}^{p}$ and $W_{e t}^{p}$ have been calculated. The results are listed in Table 7. From Table 7, it can be found that the index $W_{e t}^{p t}$ for the four specimens are $1.415,1.412,1.427$, and 1.404 , respectively. The average value is 1.415 and the percentage errors for these four specimens are in the range of $0.004 \%-0.883 \%$. Besides, the index $K_{e}$ is in the range of 1.6318-2.7066 with an average of 2.2380, while index $K_{e}^{p}$ is in the range of 0.9531-1.5914 with an average of 1.3117 . 


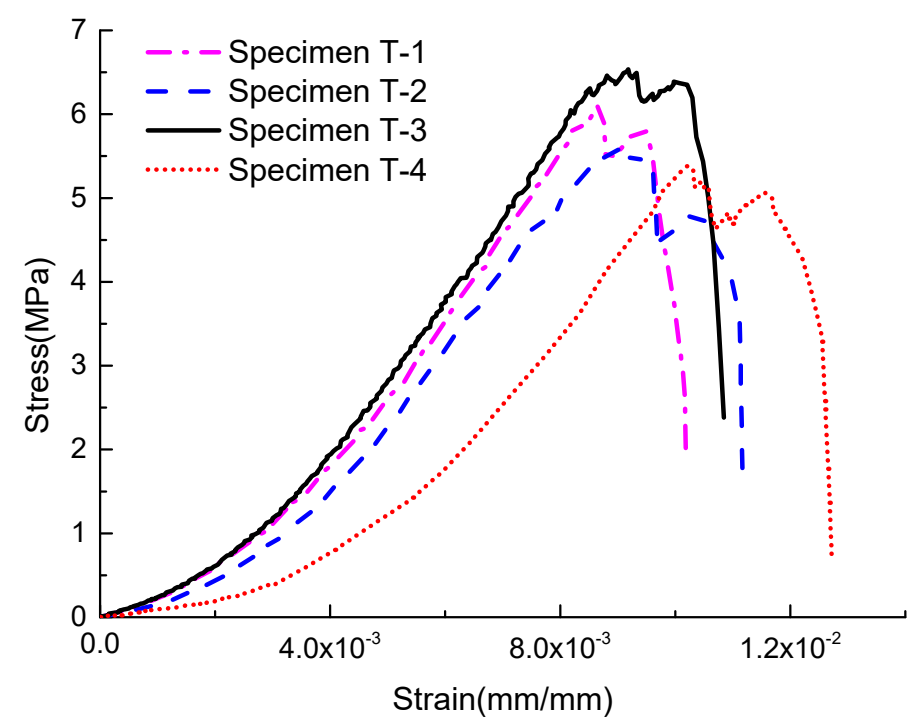

Figure 11. Stress-strain curves of four typical specimens in TJH coal mine.

Table 7. Calculated energy parameters for TJH coal mine.

\begin{tabular}{|c|c|c|c|c|c|c|c|c|c|}
\hline $\begin{array}{c}\text { Specimen } \\
\text { No. }\end{array}$ & $\begin{array}{c}R_{c} \\
\text { (MPa) }\end{array}$ & $\begin{array}{c}u \\
\left(\mathrm{~mJ} / \mathrm{mm}^{3}\right)\end{array}$ & $\begin{array}{c}u_{a} \\
\left(\mathrm{~mJ} / \mathrm{mm}^{3}\right)\end{array}$ & $\begin{array}{c}u_{a e} \\
\left(\mathrm{~mJ} / \mathrm{mm}^{3}\right)\end{array}$ & $\begin{array}{c}u_{a d} \\
\left(\mathrm{~mJ} / \mathrm{mm}^{3}\right)\end{array}$ & $\begin{array}{c}u_{r} \\
\left(\mathrm{~mJ} / \mathrm{mm}^{3}\right)\end{array}$ & $K_{e}$ & $W_{e t}^{p}$ & $K_{e}^{p}$ \\
\hline T-1 & 6.11 & 0.02919 & 0.02107 & 0.0123 & 0.0087 & 0.0081 & 2.5948 & 1.415 & 1.5202 \\
\hline $\mathrm{T}-2$ & 5.59 & 0.03058 & 0.02045 & 0.0120 & 0.0085 & 0.0101 & 2.0188 & 1.412 & 1.1819 \\
\hline $\mathrm{T}-3$ & 6.39 & 0.03509 & 0.025623 & 0.0151 & 0.0106 & 0.0095 & 2.7066 & 1.427 & 1.5914 \\
\hline $\mathrm{T}-4$ & 5.41 & 0.02966 & 0.01839 & 0.0107 & 0.0076 & 0.0113 & 1.6318 & 1.404 & 0.9531 \\
\hline
\end{tabular}

Furthermore, as shown in Table 8, the coal burst proneness grade for TJH coal mine was judged with the four indexes respectively by the Chinese standard (GB/T 25217.2-2010) [35]. It is evident that except the index $K_{\mathrm{e}}$, all the other three indexes indicate a none coal burst proneness. The average value of index $W_{e t}^{p}$ is 1.415, also meaning a none coal burst proneness because the value is lower than 2 .

Table 8. Test result and coal burst proneness of TJH coal mine.

\begin{tabular}{ccccc}
\hline Index & $\boldsymbol{D} \boldsymbol{T}(\mathbf{m s})$ & $\boldsymbol{W}_{\text {et }}$ & $\boldsymbol{K}_{\mathbf{e}}$ & $\boldsymbol{R}_{\mathbf{c}}(\mathbf{M P a})$ \\
\hline & 3039 & 1.47 & 2.59 & 6.11 \\
Test results & 3508 & 1.36 & 2.02 & 5.59 \\
& 2692 & 1.58 & 2.71 & 6.39 \\
Average & 4056 & 1.24 & 1.63 & 5.41 \\
Burst proneness & 3323.8 & 1.41 & 2.24 & 5.88 \\
\hline
\end{tabular}

Figure 12 shows the ultimate failure mode of two typical specimen in TJH coal mine. From Figure 12, only some surface cracks can be observed and there is little surface spalling after specimen failure. The specimens almost keep intact the rock status, which indicates that there is no coal burst proneness for specimens in $\mathrm{TJH}$ coal mine. However, the index $K_{\mathrm{e}}$ shows a low burst proneness, which is different from the test results. Therefore, the modified bursting energy index, with an average value of 1.3117, is more reasonable for separating the dissipated energy from the total input energy density. 

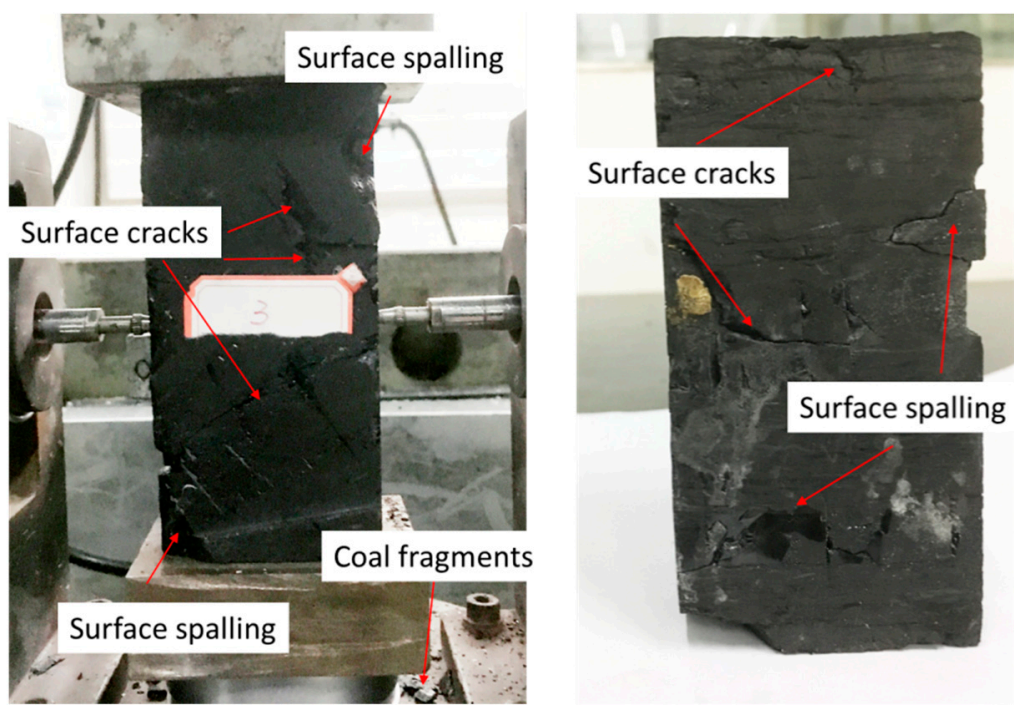

Figure 12. Ultimate failure mode of coal specimens in TJH coal mine.

\subsection{Relationship between Different Parameters}

The relationship between different parameters for coal specimens in PJ coal mine is first discussed. Figure 13 shows the relation between indexes of $K_{e}^{p}, W_{e t}^{p}$, and the uniaxial compressive strength. The linear fitting equations for these parameters are listed as follows:

$$
\begin{array}{cc}
K_{e}^{p}=0.8110 R_{c}-3.7098 & \left(R^{2}=0.7747\right) \\
W_{e t}^{p}=0.0816 R_{c}+3.0009 & \left(R^{2}=0.7304\right)
\end{array}
$$

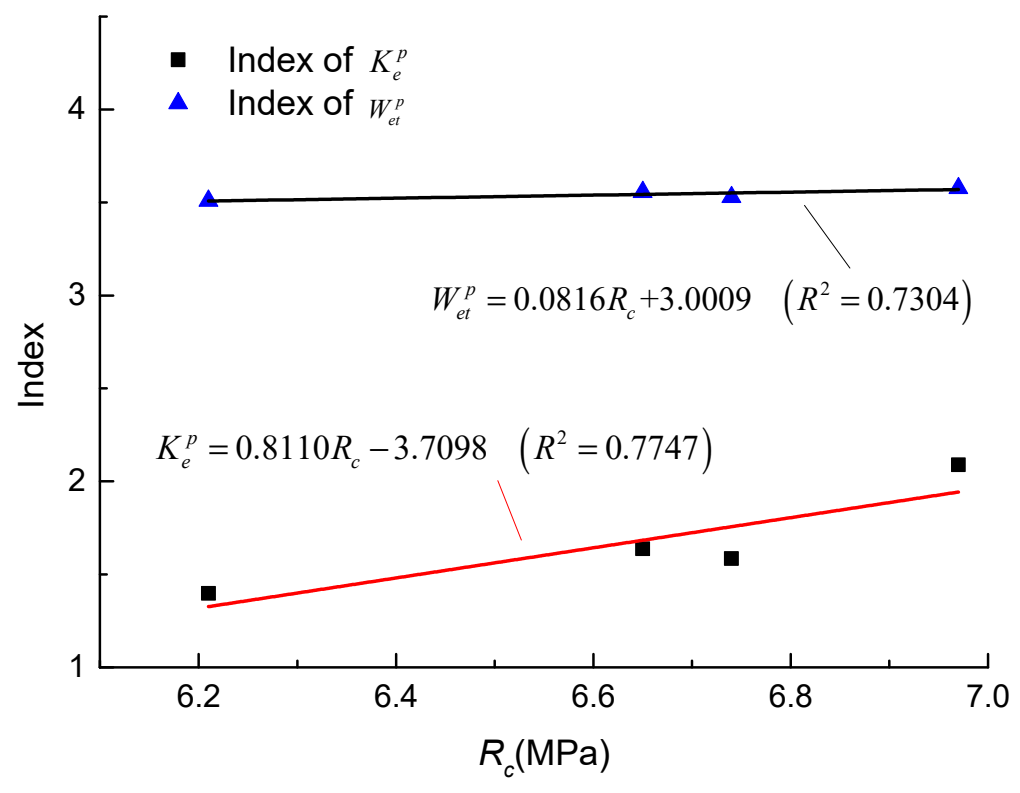

Figure 13. Relationship between indexes $K_{e}^{p}, W_{e t}^{p}$, and UCS in PJ coal mine.

From Figure 13 and Equations (17) and (18), it is clear that both the indexes $K_{e}^{p}$ and $W_{e t}^{p}$ increase linearly with increasing UCS, which agrees well with the results of Gong et al. [37]. The difference is that the slopes for indexes of $K_{e}^{p}$ and $W_{e t}^{p}$ are 0.811 and 0.0816 , respectively, indicating that the UCS has a more significant effect on the index of $K_{e}^{p}$ than that of $W_{e t}^{p}$. As illustrated before, the index $W_{e t}^{p}$ 
has a very tiny fluctuation for different specimens and it is approximate constant for a same coal type. Therefore, the fitting curve for UCS and index of $W_{e t}^{p}$ is nearly along the horizontal direction and has a small slope.

Figure 14 shows the relationship between indexes $K_{e}^{p}$ and $W_{e t^{\prime}}^{p}$ which indicates that the index $K_{e}^{p}$ increases as the index $W_{e t}^{p}$ increases. The linear fitting equation for these two parameters are listed as follows:

$$
K_{e}^{p}=8.8793 W_{e t}^{p}-29.782 \quad\left(R^{2}=0.8466\right)
$$

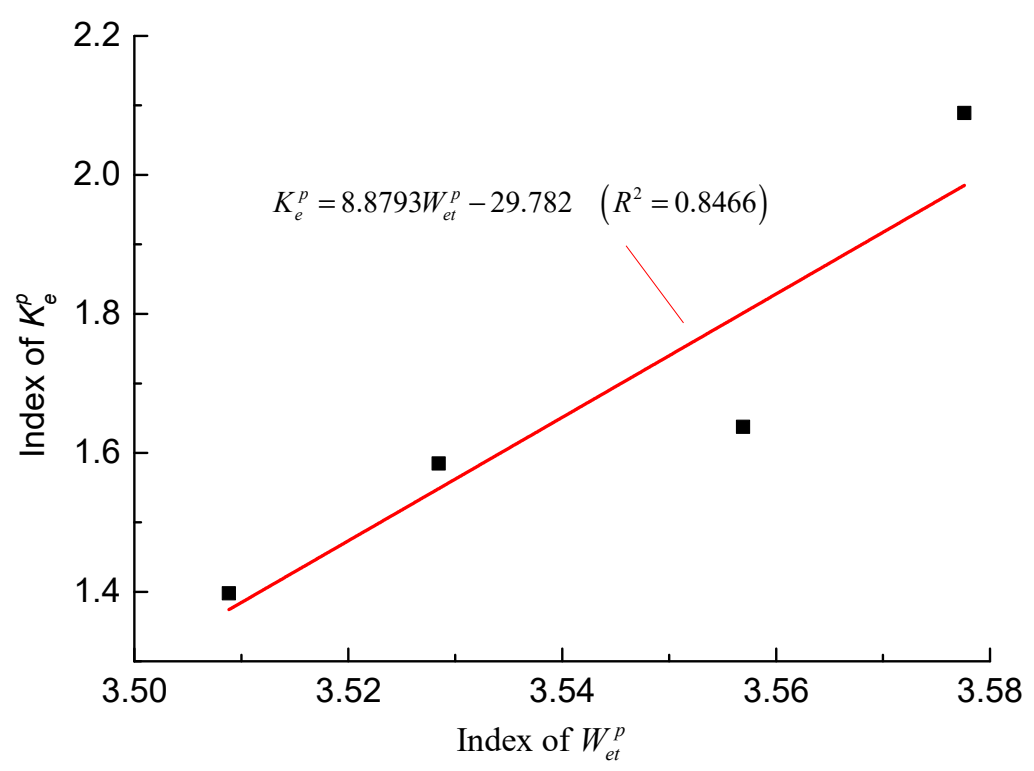

Figure 14. Relationship between indexes $K_{e}^{p}$ and $W_{e t}^{p}$ in PJ coal mine.

From Figure 14, it also can be found that the index of $K_{e}^{p}$ increases from 1.3978 to 2.0892 when the index of $W_{e t}^{p}$ increases from 3.509 to 3.578 with a correlation coefficient of 0.8466 , which means that the linear relationship between these two indexes is acceptable.

Furthermore, the relationships between different parameters for specimens in TJH coal mine have also been investigated and the fitting curves are shown in Figure 15. The results showed similar characteristics with PJ coal mine.

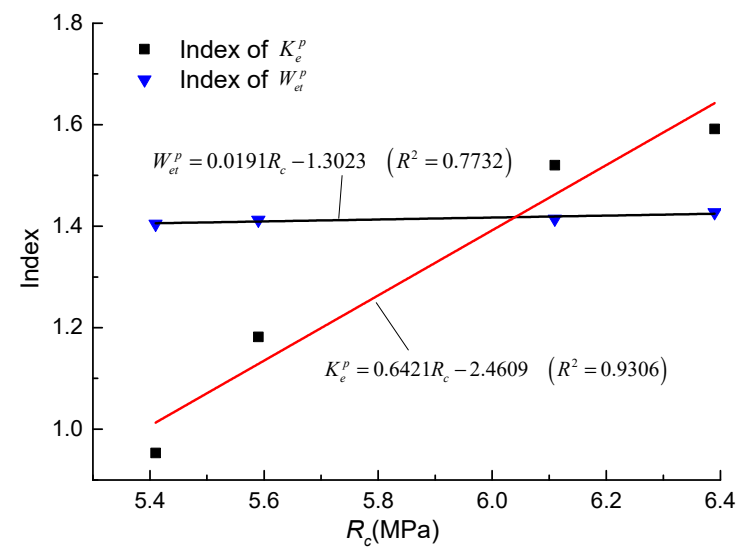

(a)

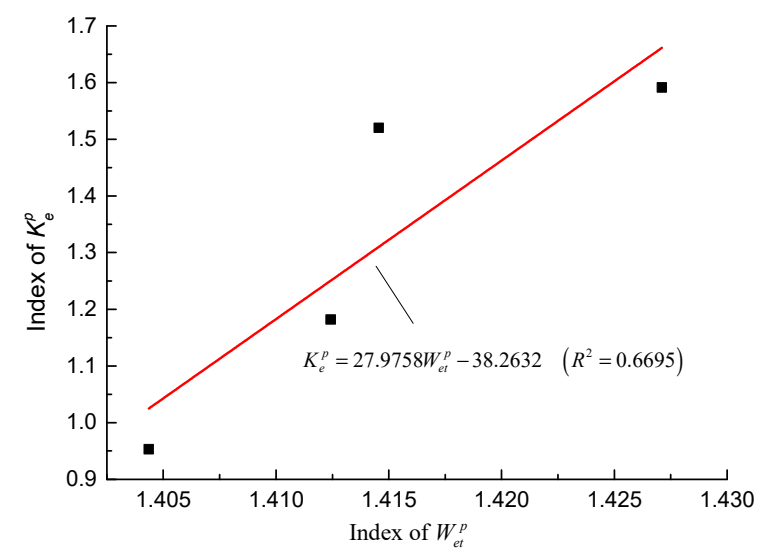

(b)

Figure 15. Relationship between different parameters in TJH coal mine: (a) Indexes $K_{e}^{p}, W_{e t}^{p}$, and UCS; (b) indexes $K_{e}^{p}$ and $W_{e t}^{p}$. 
According to the definition of peak-strength strain energy storage index in Equation (15), a higher elastic strain energy means a higher index $W_{e t}^{p}$. Therefore, the index $W_{e t}^{p}$ increases with increasing of UCS. Further, the increased index $W_{e t}^{p}$ indicates a higher ratio of elastic strain energy density to the dissipated strain energy density, which will cause a higher index $K_{e}^{p}$.

As introduced by Gong et al. [31], a greater value of parameter A indicates a higher capability of elastic strain energy storage. Actually, the parameter A relates to the strength and micro-structure of specimen. The harder the coal specimen, the fewer the primary cracks and micro-defects, and greater the parameter A. Otherwise, more primary cracks and micro-defects will cause a lower value of parameter $\mathrm{A}$. Li et al. [41] investigated the energy evolution characteristics under triaxial compression conditions and found that except the dissipative strain energy, the total input strain energy and elastic strain energy all increase as the confining pressure increases. Because the initial micro-defects and fissures were compressed by the confining pressure gradually, the increasing confining pressure changed the micro structure. Therefore, the energy density changes with a changing internal structure, which is consistent with the experimental results.

According to the definition of indexes $K_{e}^{p}$ and $W_{e t^{\prime}}^{p}$ the relation between indexes $K_{e}^{p}, W_{e t^{\prime}}^{p}$, and parameter A can be expressed by the following two equations:

$$
\begin{gathered}
K_{e}^{p}=\frac{A u_{a}+B}{u_{r}} \\
W_{e t}^{p}=\frac{A u_{a}+B}{(1-A) u_{a}+B}
\end{gathered}
$$

From Equations (20) and (21), it is easily found that both the indexes $K_{e}^{p}$ and $W_{e t}^{p}$ increases as the parameter A increases when energy parameters $u_{a}$ and $u_{r}$ remain constant. Further, the relationship between $K_{e}^{p}$ and $K_{e}$ can be deduced by combining Equations (5) and (20), and the format can be listed as follows:

$$
K_{e}^{p}=A \cdot K_{e}+\frac{B}{u_{r}}
$$

Therefore, when index $K_{e}$ remains constant, the index $K_{e}^{p}$ increases with increasing of parameter A, which can explain the different results between PJ and TJH coal mines. For the PJ coal mine, the average values of parameter $\mathrm{A}$ and $\mathrm{B}$ are 0.7419 and $-3.43 \times 10^{-4}$, respectively. In this case, the average values of indexes $K_{e}^{p}$ and $K_{e}$ are 1.6772 and 2.1502, the difference between these two indexes is 0.473 , which is not large because of a greater value of parameter $\mathrm{A}$. Therefore, both of the indexes indicate a low coal burst proneness.

For TJH coal mine, the value of parameter A is 0.5979 and the average values of indexes $K_{e}^{p}$ and $K_{e}$ are 1.3117 and 2.2380, respectively. The reducing percentage from indexes $K_{e}$ to $K_{e}^{p}$ is about $41.39 \%$. Therefore, it is easily observed that the ratio of dissipated strain energy $u_{a d}$ and the total input strain energy density $u_{a}$ is about $41.4 \%$, which causes the real coal burst proneness to be lower than that of the index $K_{e}$. In this case, the low coal burst proneness can be given by the index $K_{e}$ because it is greater than 1.5 and less than 5 . However, the modified bursting energy index $K_{e}^{p}$ indicates that there is no coal burst proneness and agrees well with the test results (shown in Figure 12), which is more reasonable because it removed the dissipated strain energy from the total input strain energy density.

\section{Conclusions}

The original bursting energy index has not distinguished the dissipated strain energy from the total input strain energy density, which may cause an overestimation for coal burst proneness. Based on the strain energy storage index at peak strength, a modified bursting energy index was proposed, and its calculation method and effectiveness were also verified by tests on two typical coal mines. The following conclusions can be drawn: 
(1) Three groups of single cyclic loading-unloading uniaxial compression tests for PJ coal mine specimens showed that the relationship between $u_{a}^{k}$ and $u_{a e}^{k}$ is linear and parameters $\mathrm{A}$ and $\mathrm{B}$ can be considered as constant for a type of coal specimen.

(2) The experimental results revealed that both the indexes of $K_{e}^{p}$ and $W_{e t}^{p}$ increase linearly as UCS increases. The difference is that the UCS has a more significant effect on index of $K_{e}^{p}$ than that of $W_{e t}^{p}$ because of the different increasing rates. Besides, the linear relationship between indexes $K_{e}^{p}$ and $W_{e t}^{p}$ was also observed.

(3) The liner fitting parameter A has a significant effect on index $K_{e}^{p}$. A large value of parameter A means more elastic strain energy before the peak strength while a small value indicates most of input energy was dissipated. When index $K_{e}$ remains constant, the index $K_{e}^{p}$ increases with the increase of parameter A.

(4) For the PJ coal mine, the average values of indexes $K_{e}$ and $K_{e}^{p}$ are 2.1502 and 1.6772. Both indexes indicate a low coal burst proneness, which is consistent with the results of index $W_{e t}^{p}$ and tests. However, for TJH coal mine, the average value of index $K_{e}$ was 2.24 and indicates a low coal burst proneness. All of other indexes, including indexes $K_{e}^{p}$ and $W_{e t}^{p}$, indicate no coal burst proneness, which agrees well with the test results. The results indicate that the modified index is more reasonable than index $K_{e}$ for coal burst proneness evaluation because it removed the dissipated strain energy from the total input strain energy density

Author Contributions: X.L.: analyzed the calculation results and wrote the article; Q.L.: review and editing; B.L.: experimental tests and discussion of the results; Y.K.: offered useful suggestions for the paper. All authors have read and agreed to the published version of the manuscript.

Funding: This work was supported by the National Nature Science Foundation of China (Grant nos: 41602324 and 51774267), Natural Science Foundation of Hubei Province (Grant no: 2019CFB535), and China Scholarship Council (Grant no: 201804910219).

Acknowledgments: We also highly appreciate the contribution of China Huaihe Energy Group for the data collection. Finally, the authors would like to thank the reviewers for their useful comments and the editors for improving the manuscript.

Conflicts of Interest: The authors declare no conflict of interest.

\section{References}

1. Mark, C. Coal bursts in the deep longwall mines of the United States. Int. J. Coal Sci. Technol. 2016, 3, 1-9. [CrossRef]

2. MacNeill, P. International Mining Fatality Database; NSW Department of Primary Industries: Sydney, Australia, 2018.

3. Jiang, Y.; Pan, Y.; Jiang, F.; Dou, L.; Ju, Y. State of the art review on mechanism and prevention of coal bumps in China. J. China Coal Soc. 2014, 39, 205-213.

4. Lu, C.-P.; Liu, G.-J.; Liu, Y.; Zhang, H. Mechanisms of Rockburst Triggered by Slip and Fracture of Coal-Parting-Coal Structure Discontinuities. Rock Mech. Rock Eng. 2019, 52, 3279-3292. [CrossRef]

5. Cui, F.; Zhang, T.; Lai, X.; Jia, C.; Shan, P. Study on the Evolution Law of Overburden Breaking Angle under Repeated Mining and the Application of Roof Pressure Relief. Energies 2019, 12, 4513. [CrossRef]

6. Tan, Y.-L.; Yin, Y.; Gu, S.; Tian, Z. Multi-Index Monitoring and Evaluation on Rock Burst in Yangcheng Mine. Shock. Vib. 2015, 2015, 1-5. [CrossRef]

7. Abdul-Wahed, M.K.; Al Heib, M.; Senfaute, G. Mining-induced seismicity: Seismic measurement using multiplet approach and numerical modeling. Int. J. Coal Geol. 2006, 66, 137-147. [CrossRef]

8. Xu, X.; Dou, L.; Lu, C.; Zhang, Y. Frequency spectrum analysis on micro-seismic signal of rock bursts induced by dynamic disturbance. Min. Sci. Technol. (China) 2010, 20, 682-685. [CrossRef]

9. Lu, C.-P.; Dou, L.-M.; Cao, A.-Y.; Wu, X.-R. Research on microseismic activity rules in Sanhejian Coal Mine. J. Coal Sci. Eng. (China) 2008, 14, 373-377. [CrossRef]

10. Yu, Y.; Chen, B.-R.; Xu, C.-J.; Diao, X.-H.; Tong, L.; Shi, Y.-F. Analysis for Microseismic Energy of Immediate Rockbursts in Deep Tunnels with Different Excavation Methods. Int. J. Géoméch. 2017, 17, 04016119. [CrossRef] 
11. Ding, Y.; Dou, L.; Cai, W.; Chen, J.; Kong, Y.; Su, Z.; Li, Z. Signal characteristics of coal and rock dynamics with micro-seismic monitoring technique. Int. J. Min. Sci. Technol. 2016, 26, 683-690. [CrossRef]

12. Zhang, H.; Chen, L.; Chen, S.; Sun, J.; Yang, J. The Spatiotemporal Distribution Law of Microseismic Events and Rockburst Characteristics of the Deeply Buried Tunnel Group. Energies 2018, 11, 3257. [CrossRef]

13. Cao, A.-Y.; Dou, L.-M.; Wang, C.-B.; Yao, X.-X.; Dong, J.-Y.; Gu, Y. Microseismic Precursory Characteristics of Rock Burst Hazard in Mining Areas Near a Large Residual Coal Pillar: A Case Study from Xuzhuang Coal Mine, Xuzhou, China. Rock Mech. Rock Eng. 2016, 49, 4407-4422. [CrossRef]

14. Wang, E.; He, X.; Wei, J.; Nie, B.; Song, D. Electromagnetic emission graded warning model and its applications against coal rock dynamic collapses. Int. J. Rock Mech. Min. Sci. 2011, 48, 556-564. [CrossRef]

15. Wang, E.; He, X.; Liu, X.; Li, Z.; Wang, C.; Xiao, N. A non-contact mine pressure evaluation method by electromagnetic radiation. J. Appl. Geophys. 2011, 75, 338-344. [CrossRef]

16. Song, D.; Wang, E.; Li, Z.; Qiu, L.; Xu, Z. EMR: An effective method for monitoring and warning of rock burst hazard. Géoméch. Eng. 2017, 12, 53-69. [CrossRef]

17. Wang, E.; He, X.; Liu, X.; Xu, W. Comprehensive monitoring technique based on electromagnetic radiation and its applications to mine pressure. Saf. Sci. 2012, 50, 885-893. [CrossRef]

18. Li, X.; Wang, E.; Li, Z.; Liu, Z.; Song, D.; Qiu, L. Rock Burst Monitoring by Integrated Microseismic and Electromagnetic Radiation Methods. Rock Mech. Rock Eng. 2016, 49, 4393-4406. [CrossRef]

19. Wei, C.; Zhang, C.; Canbulat, I.; Cao, A.; Dou, L. Evaluation of current coal burst control techniques and development of a coal burst management framework. Tunn. Undergr. Space Technol. 2018, 81, 129-143. [CrossRef]

20. Hendon, G. Gateroad pillar extraction experience at Jim Walter Resources. In Proceedings of the 17th International Conference on Ground Control in Mining, Morgantown, WV, USA, 4-6 August 1998; pp. 1-10.

21. Mark, C.; Gauna, M. Evaluating the risk of coal bursts in underground coal mines. Int. J. Min. Sci. Technol. 2016, 26, 47-52. [CrossRef]

22. Koehler, J.; DeMarco, M.; Wuest, W. Critical pillar concept in yield-pillar-based longwall gate-road design. Min. Eng. 1996, 48, 73-78.

23. Iannacchione, A.; Tadolini, S.C. Coal mine burst prevention controls. In Proceedings of the 27th International Conference on Ground Control in Mining, Morgantown, WV, USA, 29-31 July 2008; pp. 20-28.

24. Pan, J.; Ning, Y.; Du, T.; Zhang, Y.; Liu, J.; Xia, Y.; Wei, X. The theory and system for preventing rock burst in large-scale areas. J. China Coal Soc. 2012, 37, 1803-1809.

25. Kaiser, P.K.; Cai, M. Design of rock support system under rockburst condition. J. Rock Mech. Geotech. Eng. 2012, 4, 215-227. [CrossRef]

26. Fan, J.; Dou, L.; He, H.; Du, T.; Zhang, S.; Gui, B.; Sun, X. Directional hydraulic fracturing to control hard-roof rockburst in coal mines. Int. J. Min. Sci. Technol. 2012, 22, 177-181. [CrossRef]

27. He, M.; Xia, H.; Jia, X.; Gong, W.; Zhao, F.; Liang, K. Studies on classification, criteria and control of rockbursts. J. Rock Mech. Geotech. Eng. 2012, 4, 97-114. [CrossRef]

28. He, H.; Dou, L.; Fan, J.; Du, T.; Sun, X. Deep-hole directional fracturing of thick hard roof for rockburst prevention. Tunn. Undergr. Space Technol. 2012, 32, 34-43. [CrossRef]

29. Dai, S.; Wang, X.; Pan, Y. Experimental study on the evaluation of coal burst tendency utilizing modulus index. J. China Coal Soc. 2019, 44, 1726-1731.

30. Xu, J.; Jiang, J.; Xu, N.; Liu, Q.; Gao, Y. A new energy index for evaluating the tendency of rockburst and its engineering application. Eng. Geol. 2017, 230, 46-54. [CrossRef]

31. Gong, F.; Yan, J.; Li, X.; Luo, S. A peak-strength strain energy storage index for rock burst proneness of rock materials. Int. J. Rock Mech. Min. Sci. 2019, 117, 76-89. [CrossRef]

32. Wang, J.-A.; Park, H. Comprehensive prediction of rockburst based on analysis of strain energy in rocks. Tunn. Undergr. Space Technol. 2001, 16, 49-57. [CrossRef]

33. Yang, X.; Ren, T.; Tan, L.; Remennikov, A.; He, X. Developing coal burst propensity index method for Australian coal mines. Int. J. Min. Sci. Technol. 2018, 28, 783-790. [CrossRef]

34. Su, C.D.; Yuan, R.F.; Zhai, X.X. Experimental research bursting liability index of coal samples of Chengjiao coal mine. Chin. J. Rock Mech. Eng. 2013, 32, 3692-3704.

35. Classification and Laboratory Test Method on Bursting Liability of Coal; GB/T 25217.2-2010; Standards Press of China: Beijing, China, 2010.

36. Zhang, C.Q.; Lu, J.J.; Chen, J.; Zhou, H.; Yang, F.J. Discussion on rock burst proneness indexes and their relation. Rock Soil Mech. 2017, 38, 1397-1404. 
37. Gong, F.; Yan, J.; Luo, S.; Li, X. Investigation on the Linear Energy Storage and Dissipation Laws of Rock Materials Under Uniaxial Compression. Rock Mech. Rock Eng. 2019, 52, 4237-4255. [CrossRef]

38. Fairhurst, C.E.; Hudson, J.A. Draft ISRM suggested method for the complete stress-strain curve for intact rock in uniaxial compression. Int. J. Rock Mech. Min. Sci. 1999, 36, 281-289.

39. Liang, C.Y.; Zhang, Q.B.; Li, X.; Xin, P. The effect of specimen shape and strain rate on uniaxial compressive behavior of rock material. Bull. Int. Assoc. Eng. Geol. 2015, 75, 1669-1681. [CrossRef]

40. Zhai, S.; Su, G.; Yin, S.; Zhao, B.; Yan, L. Rockburst characteristics of several hard brittle rocks: A true triaxial experimental study. J. Rock Mech. Geotech. Eng. 2020. [CrossRef]

41. Li, D.; Sun, Z.; Xie, T.; Li, X.; Ranjith, P. Energy evolution characteristics of hard rock during triaxial failure with different loading and unloading paths. Eng. Geol. 2017, 228, 270-281. [CrossRef]

(C) 2020 by the authors. Licensee MDPI, Basel, Switzerland. This article is an open access article distributed under the terms and conditions of the Creative Commons Attribution (CC BY) license (http://creativecommons.org/licenses/by/4.0/). 